1 Supporting Information

2

3

4

5

6

13 Figure S1. Results with the original DICE damage function versus the Immediate Damage

\section{What role do the impacts from high emissions and high temperatures have on choosing optimal mitigation targets?}

\author{
Jonghyun Yoo ${ }^{a, b}$, Robert Mendelsohn ${ }^{a, *}$
}

a. Yale School of the Environment, 195 Prospect Street, New Haven, CT, 06511, USA.

b: Department of Urban Planning and Design, University of Seoul, 163 Seoulsiripdaero,

Dongdaemun-gu, Seoul, 02504, Korea.

*: Corresponding author, robert.mendelsohn@yale.edu

\section{Table of Contents}

Function.

Figure S2. Results with the original DICE damage function versus the High Damage function .S4

Figure S3 Sensitivity Analysis - Surface Temperature $\left({ }^{\circ} \mathrm{C}\right)$

Figure S4 Sensitivity Analysis - Carbon Price (2005 USD/tCO 2 ........

Figure S5 Sensitivity Analysis - Carbon Control Rate (\% of global emissions) S3 .S6 .S8 S10 
This supplement examines the detailed outputs of DICE in a range of scenarios. The

23 analysis begins with a comparison of the outcome with the original DICE 2016 damage function

24 model $^{1}$ versus the Immediate Damage. The Immediate Damage assumes damage rises rapidly as

25 temperature warms from their current observed level to $3^{\circ} \mathrm{C}$ which causes damage to equal GDP.

26 Upper left panel in Figure S1 examines the path of global temperature in both scenarios. The

27 Immediate Damage causes enough mitigation to depress global temperatures and hold them to

$282.1^{\circ} \mathrm{C}$ by 2100 . The original DICE model allows optimal temperatures to rise to $3.5^{\circ} \mathrm{C}$. Upper

29 right panel examines the carbon price over time. The carbon price with the original DICE

30 damage function model appears flat and low (below $\$ 300 / \mathrm{tCO}_{2}$ ) through 2100 but this is simply

31 relative to the carbon price encouraged by the Immediate Damage which starts at $\$ 2,000 / \mathrm{tCO}_{2}$ in

322020 and rises. Lower left panel examines the mitigation path. Because there are already enough

33 greenhouse gases in the atmosphere to reach the $2^{\circ} \mathrm{C}$ temperature target, the Immediate Damage

34 suggests the optimal strategy is to immediately eliminate carbon emissions and move to a carbon

35 neutral economy. The DICE model in contrast starts with removing about $25 \%$ of global

36 emission immediately and moving to a carbon neutral economy by 2110 . Lower right panel

37 examines the climate damage one should observe given the mitigation policy. The original DICE

38 damage function model suggests that annual climate damage (market plus nonmarket) as a

39 fraction of GDP is $0.2 \%$ in 2020 and rises to about $2.9 \%$ of GDP by 2100 . With the Immediate

40 Damage, the annual climate damage is $0.3 \%$ in 2020 and rises to $21.7 \%$ of GDP by 2100 . 


\section{Figure S1. Results with the original DICE damage function versus the 43 Immediate Damage Function \\ 44}
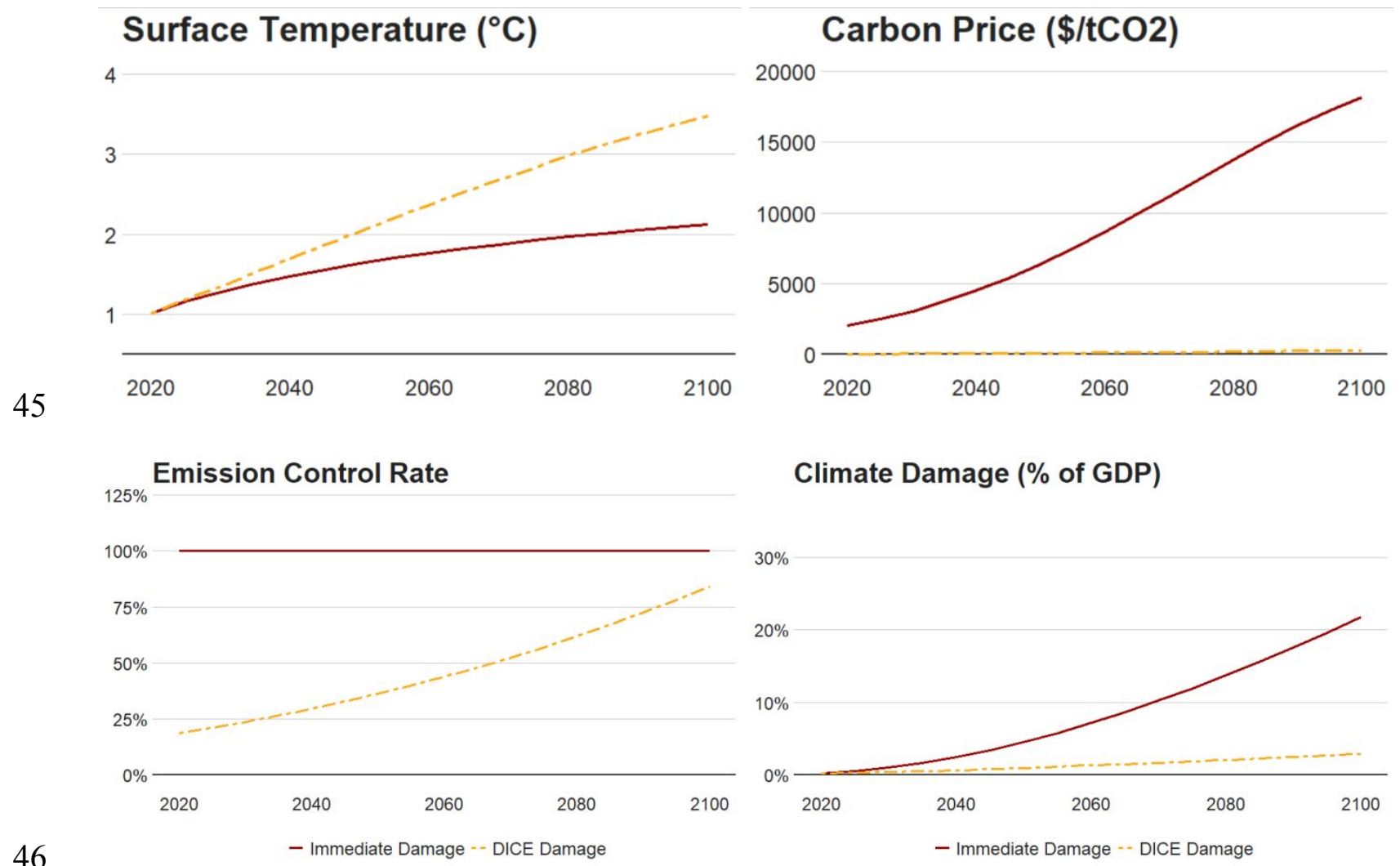

Climate Damage (\% of GDP)

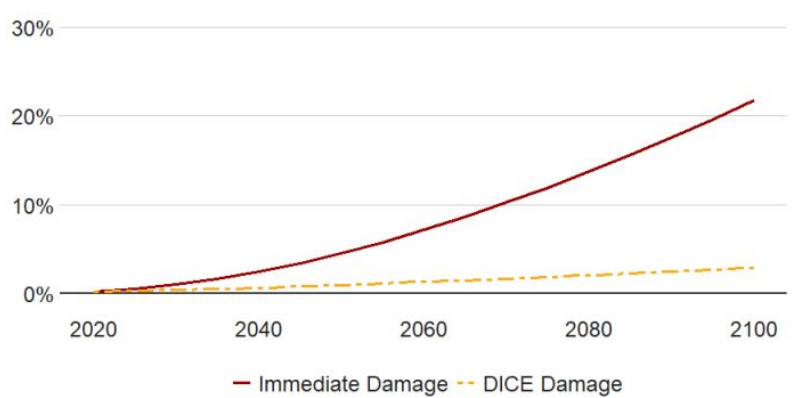

47 Note: Compares the original DICE model and the Immediate Damage scenario.

Figure S2 compares the detailed results of the original DICE damage function to the

50 results with the High Damage which suggests damage rises rapidly once temperatures reach $4^{\circ} \mathrm{C}$.

51 With the High Damage, a temperature of $7^{\circ} \mathrm{C}$ causes annual damage to equal GDP, a catastrophe.

52 Upper left panel in Figure S2 shows the global temperature path will be the same between the

53 original DICE model and the High Damage model. The temperature in 2100 will be $3.5^{\circ} \mathrm{C}$ in

54 both models. The path of carbon price (upper right) and the path of mitigation (lower left) are

55 also very similar. Carbon price in 2020 is $\$ 38 / \mathrm{tCO}_{2}$ and reduces $5 \%$ global emissions in both

56 scenarios. DICE suggests raising the price to $\$ 271 / \mathrm{tCO}_{2}$ and cutting $84 \%$ of global emissions by 
57 2100. The High Damage model proposes $\$ 297 / \mathrm{tCO}_{2}$ and $89 \%$ of emission reduction by 2100 .

58 Lower right panel presents the global climate damage. The damage will be about $3 \%$ by 2100 in 59 both scenarios.

60

61 Figure S2. Results with the original DICE damage function versus the 62 High Damage function

63

Surface Temperature $\left({ }^{\circ} \mathrm{C}\right)$

4

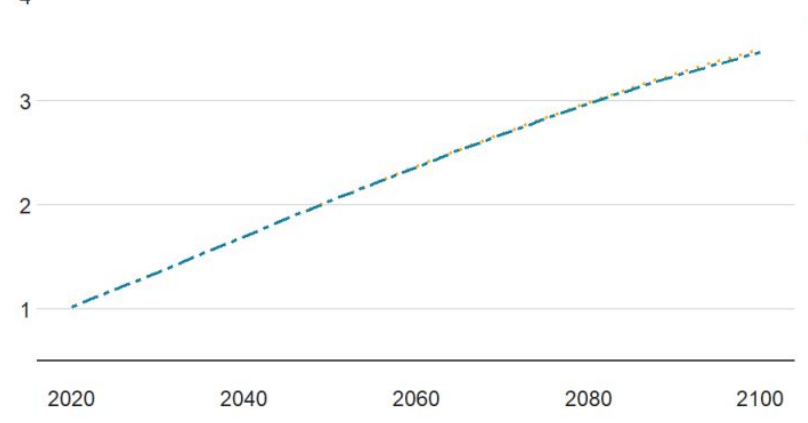

64
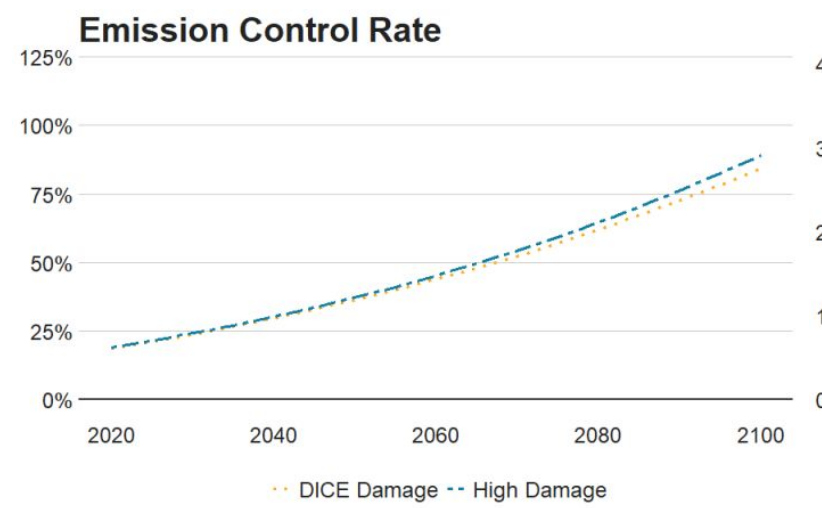

Carbon Price $(\$ / \mathrm{tCO})$

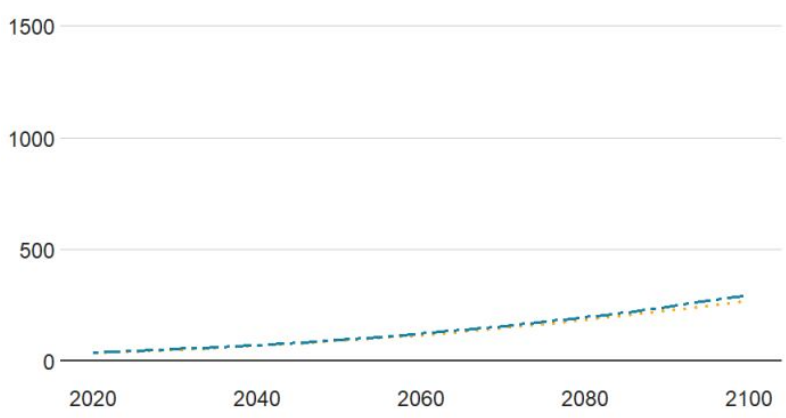

Climate Damage (\% of GDP)

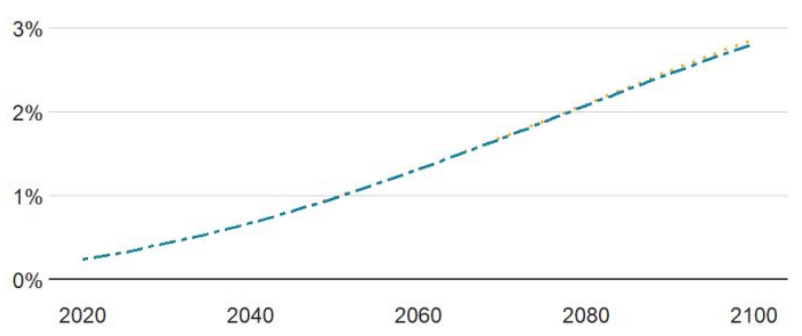

- DICE Damage -- High Damage
65

66

67

68

69

70

71

Note: Compares the original DICE model and the High Damage scenario.

Figure S3-A6 compare the optimal paths with the DICE damage function and the High

Damage for alternative scenarios. Figure S3 particularly examines the path of global

temperatures by 2100 . Upper left panel in Figure S3 assumes a 2\% discount rate and shows the identical temperature path between the DICE Damage and the High Damage. They both suggest 
72 that temperatures slowly increase over time and reach $2.5^{\circ} \mathrm{C}$ by 2100 . When assuming a higher

73 discount rate $5 \%$ (upper right panel), the 2100 temperature target will be higher than the $2 \%$ rate

74 because the future climate damage is discounted more. The DICE damage model suggests a

75 slightly higher temperature target $\left(3.7^{\circ} \mathrm{C}\right)$ in 2100 than the temperature target with the High

76 Damage model $\left(3.6^{\circ} \mathrm{C}\right)$. Each panel in the middle of Figure $\mathrm{S} 3$ explores a scenario of cheaper

77 mitigation or more expensive mitigation. If mitigation is cheap, society can cut emissions at low

78 cost and it is relatively easy to depress global temperatures. Consequences at high temperatures

79 (over $4^{\circ} \mathrm{C}$ ) are irrelevant. Both the DICE damage and the High Damage models suggest the same

80 temperature path. The temperature goal by 2100 is $3.1^{\circ} \mathrm{C}$. If the mitigation is twice as expensive,

81 it is relatively difficult to keep temperatures low. However, it is enough to hold temperatures

82 below $4^{\circ} \mathrm{C}$ by 2100 . The DICE model suggests a slightly higher 2100 temperature, $3.8^{\circ} \mathrm{C}$, than the

83 High Damage model, $3.6^{\circ} \mathrm{C}$. Lower panels examine alternative equilibrium climate sensitivity

84 scenarios, $1.5^{\circ} \mathrm{C}$ and $4.5^{\circ} \mathrm{C}$, the lower and the upper bound of the IPCC's likely range ${ }^{2}$. If the

85 climate is not sensitive to carbon emission (lower left panel), temperatures will not increase

86 rapidly over time. High temperatures are unlikely. Both models suggest a $2.3^{\circ} \mathrm{C}$ temperature for

87 2100. If the climate is sensitive to carbon emission, temperatures will rapidly rise. The DICE

88 damage model suggests a $4.0^{\circ} \mathrm{C}$ target for 2100 . However, the High Damage assumes far larger

89 damages above $4^{\circ} \mathrm{C}$. It keeps the global temperature in 2100 to $3.6^{\circ} \mathrm{C}$.

90 
91 Figure S3 Sensitivity Analysis - Surface Temperature $\left({ }^{\circ} \mathrm{C}\right)$
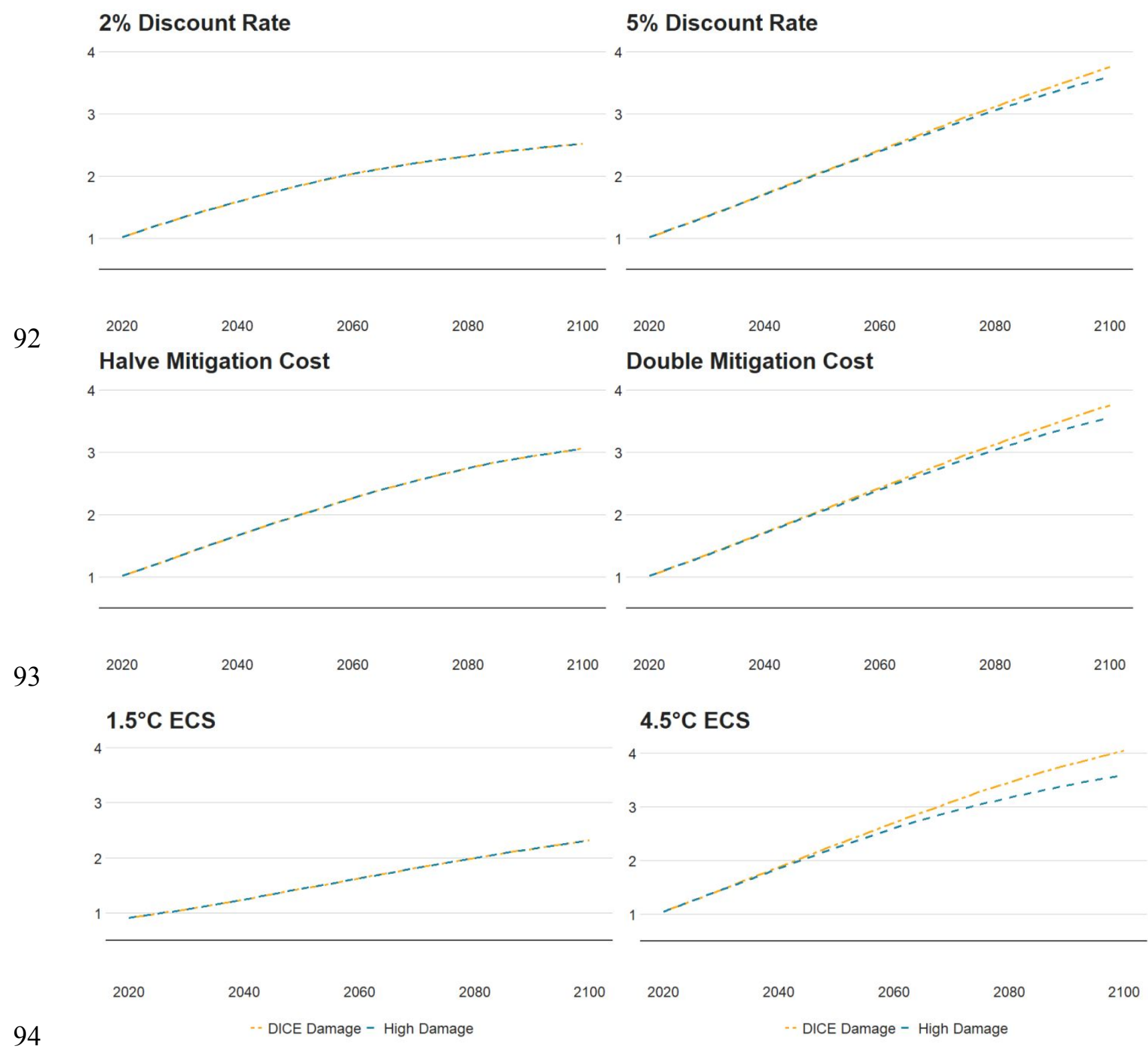

95 Note: Compares the original DICE damage function and the High Damage function. 
Figure S4 compares the carbon price path for each scenario. As shown in Figure S3, the

97 High Damage does not change the temperature path for the $2 \%$ discount rate, the halved

98 mitigation cost, and the $1.5^{\circ} \mathrm{C}$ equilibrium climate sensitivity scenarios. The DICE damage and

99 the High Damage model suggest the same carbon price path for those scenarios as well. For the

100 other three scenarios, the $5 \%$ discount rate, the doubled mitigation cost, and the $4.5^{\circ} \mathrm{C}$

101 equilibrium climate sensitivity, however, the carbon price path for the DICE damage function is

102 below the carbon price path for the High Damage. The upper right panel presents the case of a

$1035 \%$ discount rate. The price with the DICE damage function begins with $\$ 23 / \mathrm{tCO}_{2}$ in 2020 which

104 rises to $\$ 105 / \mathrm{tCO}_{2}$ in 2100 . The High Damage model suggests the carbon price is $\$ 26 / \mathrm{tCO}_{2}$ in

1052020 and rises to $\$ 266 / \mathrm{tCO}_{2}$ in 2100 . The middle right panel shows the carbon price path for a

106 scenario with higher cost of mitigation. The carbon price with the DICE damage increases from

$107 \$ 37 / \mathrm{tCO}_{2}$ in 2020 to $\$ 271 / \mathrm{tCO}_{2}$ in 2100 . The carbon price with the High Damage increases from

$108 \$ 50 / \mathrm{tCO}_{2}$ in 2020 to $\$ 580 / \mathrm{tCO}_{2}$ in 2100 . The lower right panel shows the different price paths for

109 the $4.5^{\circ} \mathrm{C}$ equilibrium climate sensitivity scenario. The DICE damage model starts with $\$ 58 / \mathrm{tCO}_{2}$

110 in 2020 and reaches $\$ 452 / \mathrm{tCO}_{2}$ in 2100 . However, the High Damage model starts with $\$ 87 / \mathrm{tCO}_{2}$

111 in 2020 and rapidly increases to $\$ 1,108 / \mathrm{tCO}_{2}$ in 2100 . The higher prices with the High Damage

112 are caused by the far larger damages above $4^{\circ} \mathrm{C}$. When expecting temperatures to exceed $4^{\circ} \mathrm{C}$ in

113 the long run, the DICE model anticipates this by setting higher prices even before temperatures

114 reach $4^{\circ} \mathrm{C}$.

115 


\section{Figure S4 Sensitivity Analysis - Carbon Price (2005 USD/tCO ${ }_{2}$ )}

118
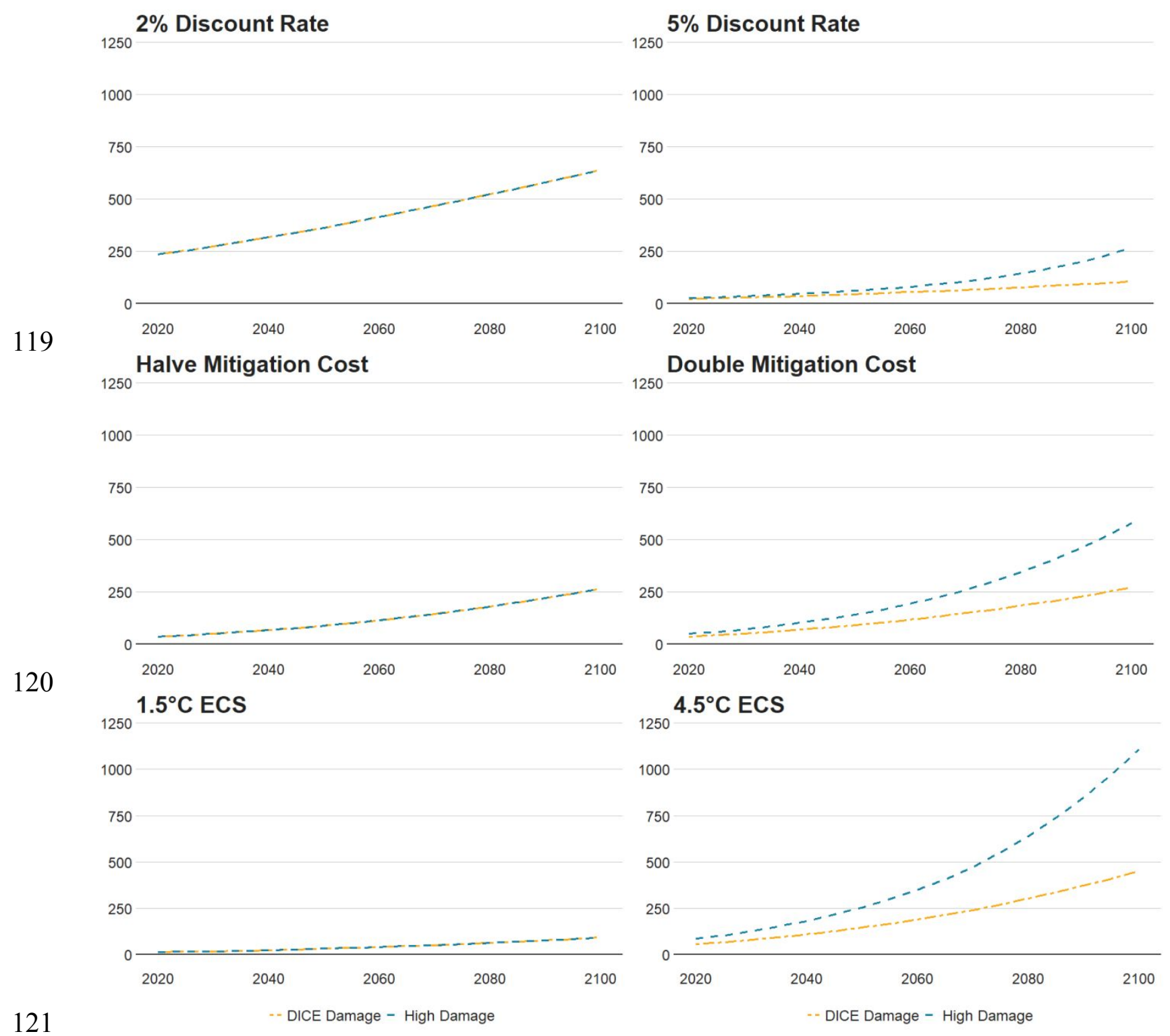

122 Note: Compares the original DICE damage function and the High Damage function. 
124 scenarios (the $2 \%$ discount rate, the halved mitigation cost, the $1.5^{\circ} \mathrm{C}$ equilibrium climate

125 sensitivity) that show the same temperature path between the two damage functions also show

126 the same mitigation path. However, the other three scenarios (the 5\% discount rate, the doubled

127 mitigation cost, the $4.5^{\circ} \mathrm{C}$ equilibrium climate sensitivity) show quite different paths between the

128 two damage functions. The upper right panel examines the 5\% discount rate. The DICE damage

129 function increases the mitigation efforts from $14 \%$ in 2020 to $47 \%$ in 2100 . The High Damage

130 starts with almost the same amount of mitigation in $2020,15 \%$, but it rapidly increases the

131 mitigation effort to $83 \%$ by 2100 . The doubled mitigation cost scenario (middle right panel)

132 shows a similar outcome. The control rate increases gradually from $12 \%$ to $55 \%$ with the DICE

133 damage function. The High Damage leads to slightly more mitigation in $2020,15 \%$, but rapidly

134 increases from $15 \%$ to $88 \%$ by 2100 . The higher climate sensitivity in the lower right panel leads

135 to more stringent mitigation. The DICE damage function removes all emissions by 2095 . The

136 High Damage model suggests achieving this zero-carbon economy in 2070, 25 years earlier. 


\section{Figure S5 Sensitivity Analysis - Carbon Control Rate (\% of global 139 emissions)}

140

141
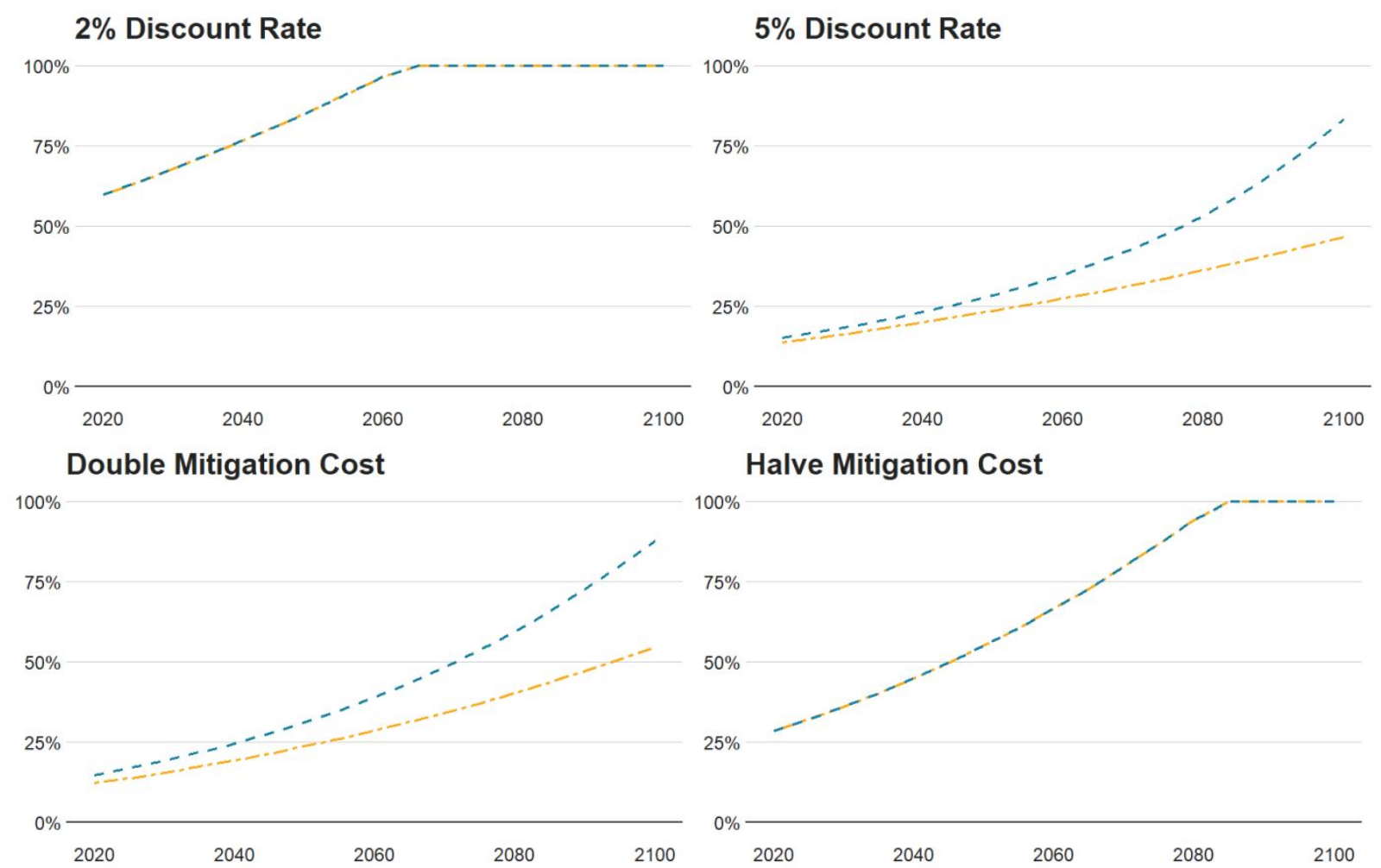

142

\section{$1.5^{\circ} \mathrm{C} \mathrm{ECS}$}

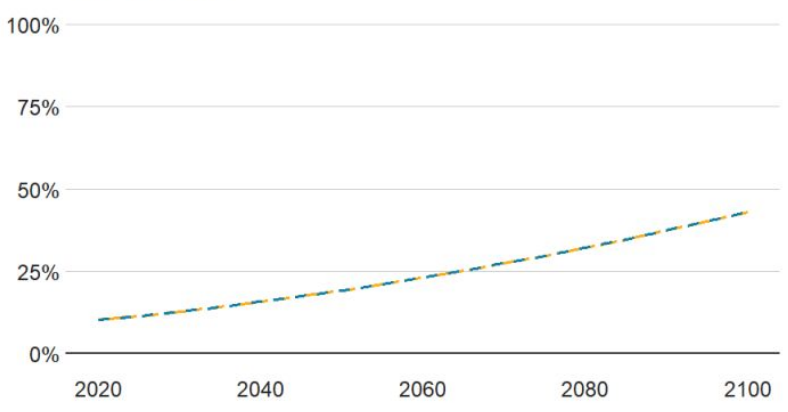

143

-- DICE Damage - High Damage

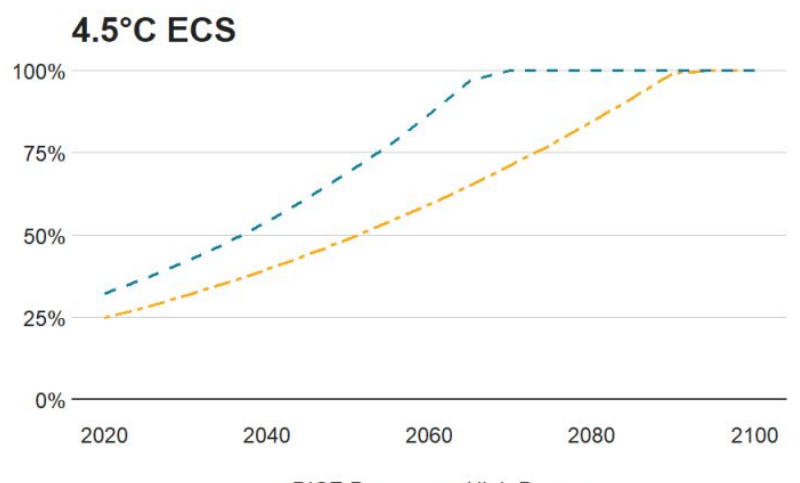

144 Note: Compares the original DICE damage function and the High Damage function. 
147 difference in the path is found for the three unchanging scenarios (the $2 \%$ discount rate, the 148 halved mitigation cost, the $1.5^{\circ} \mathrm{C}$ equilibrium climate sensitivity). There are changes in the path 149 of annual damage in the $5 \%$ discount rate, doubled mitigation cost, and $4.5^{\circ} \mathrm{C}$ scenarios. In all 150 three scenarios, the path is the same through 2050 and then the two damage paths slowly diverge.

151 Even though the High Damage leads to more severe damage than the DICE damage function 152 once temperatures exceed $4^{\circ} \mathrm{C}$, the annual climate damage is slightly higher with the DICE 153 damage function than the High Damage. The path of temperatures starts to diverge after 2050 154 causing the damage under the High Damage to be lower than under the DICE damage function. 155 Temperatures this century remain below $4^{\circ} \mathrm{C}$ so annual damages are lower with the High 156 Damage. In the 5\% discount rate and doubled mitigation cost scenarios, annual damages are $1573.3 \%$ of GDP with the DICE damage function and about $3.1 \%$ with the High Damage. In the $1584.5^{\circ} \mathrm{C}$ equilibrium climate sensitivity scenario, 2100 annual damage is $3.9 \%$ with the DICE 159 damage function and 3.0\% with the High Damage. 
161 Figure S6 Sensitivity Analysis - Climate Damage (\% of GDP)

162
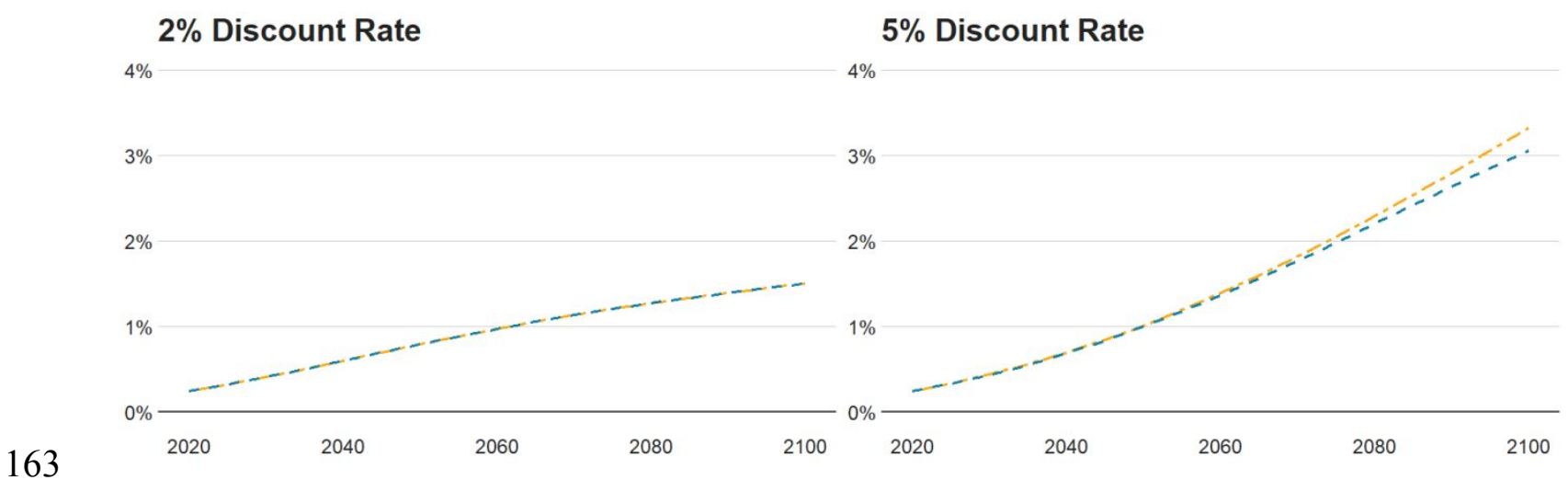

\section{Halve Mitigation Cost}

$4 \%$

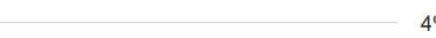

Double Mitigation Cost

164
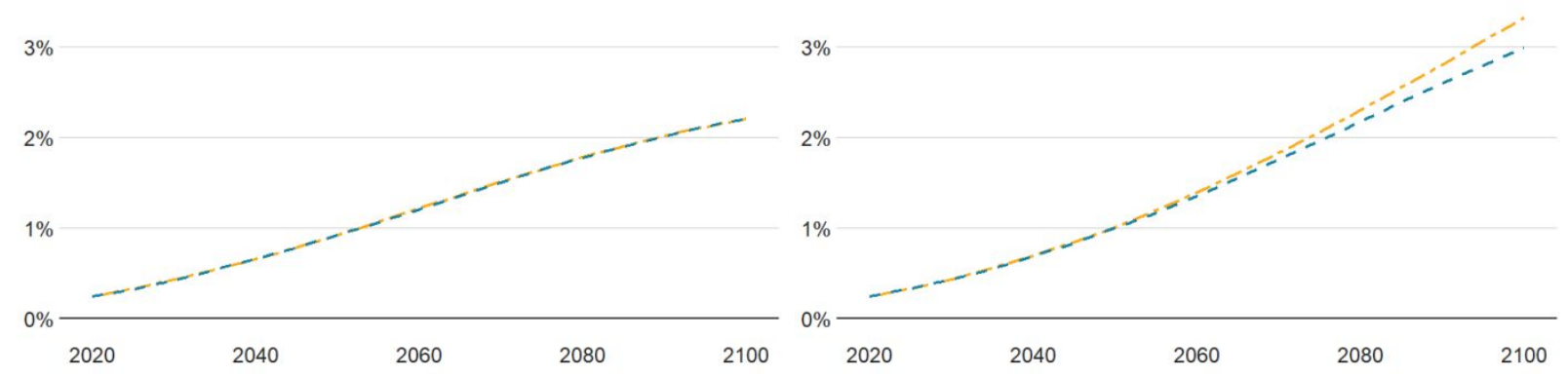

$1.5^{\circ} \mathrm{C} \mathrm{ECS}$

$4.5^{\circ} \mathrm{C} \mathrm{ECS}$

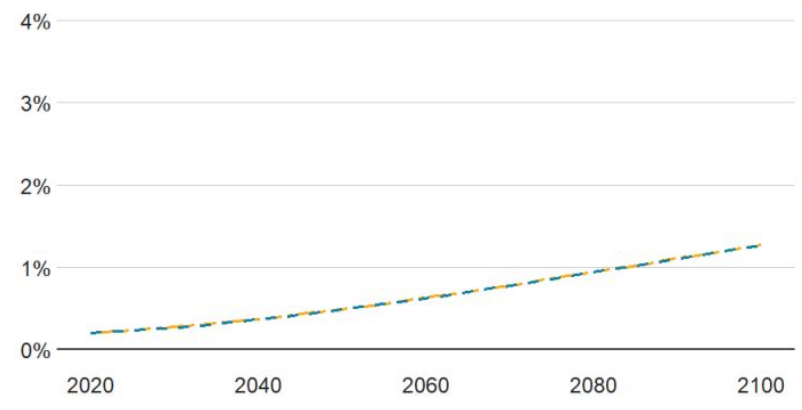

165

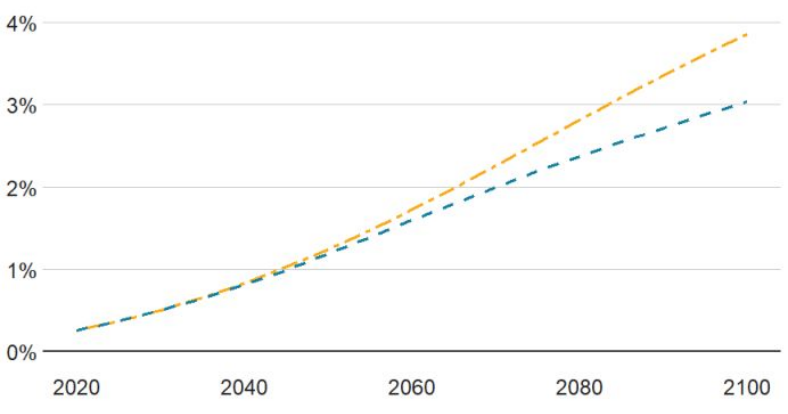

166 Note: Compares the original DICE damage function and the High Damage function. 


\section{Reference}

168

1691 Nordhaus, W. D. Revisiting the social cost of carbon. Proceedings of the National

$170 \quad$ Academy of Sciences 114, 1518-1523, doi:10.1073/pnas.1609244114 (2017).

1712 IPCC. Climate Change 2014: Synthesis Report. Contribution of Working Groups I, II and

172

173 III to the Fifth Assessment Report of the Intergovernmental Panel on Climate Change.

174 